\title{
Crystal Structure of the Sugar Binding Domain of the Archaeal Transcriptional Regulator TrmB*
}

Received for publication, November 30, 2005, and in revised form, February 9, 2006 Published, JBC Papers in Press, February 10, 2006, DOI 10.1074/jbc.M512809200

\author{
Michael Krug, Sung-Jae Lee, Kay Diederichs, Winfried Boos, and Wolfram Welte \\ From the Department of Biology, University of Konstanz, 78457 Konstanz, Germany
}

$\operatorname{TrmB}$ is an $\boldsymbol{\alpha}$-glucoside-sensing transcriptional regulator controlling two operons encoding maltose/trehalose and maltodextrin ABC transporters of Pyrococcus furiosus. The crystal structure of an $\mathrm{N}$-terminal truncated derivative of $\operatorname{TrmB}$ (amino acids 2-109 deleted; $\left.\operatorname{TrmB}_{\Delta 2-109}\right)$ was solved at $1.5 \AA$ resolution. This protein has lost its DNA binding domain but has retained its sugar recognition site. The structure represents a novel sugar-binding fold. $\operatorname{TrmB}_{\Delta 2-109}$ bound maltose, glucose, sucrose, and maltotriose, exhibiting $K_{d}$ values of $6.8,25,34$, and $160 \mu \mathrm{M}$, respectively. $\operatorname{TrmB}_{\Delta 2-109}$ behaved as a monomer in dilute buffer solution in contrast to the full-length protein, which is a dimer. Co-crystallization with bound maltose identified a binding site involving seven amino acid residues: $\operatorname{Ser}^{229}$, $\mathrm{Asn}^{305}, \mathrm{Gly}^{320}, \mathrm{Met}^{321}, \mathrm{Val}^{324}, \mathrm{Ile}^{325}$, and Glu ${ }^{326}$. Six of these residues interact with the nonreducing glucosyl residue of maltose. The nonreducing glucosyl residue is shared by all substrates bound to $\operatorname{TrmB}$, suggesting it as a common recognition motif.

Gene expression in archaea (1-4) relies on a eukaryotic-like transcription machinery and eukaryotic-like promoter elements but bacterial-like regulatory transcription factors $(4-8)$. Several archaeal transcription regulators have been reported (9). One type is homologous to the Lrp/AsnC family (10). Lrs14 and LysM have been identified in the hyperthermophilic crenarchaeoton Sulfolobus solfataricus (11, 12), LrpA in the hyperthermophilic euryarchaeoton Pyrococcus furiosus (10), and Ptr1 and Ptr2 in Methanococcus jannaschii (13). NrpR, a repressor of nif expression in Methanococcus maripaludis has been shown to recognize two tandem operators and to be released from binding by 2-oxoglutarate (14). Others are the metal-dependent regulator (MDR1) from Archaeoglobus fulgidus (15), a tryptophan-sensitive transcription regulator TrpY from Methanothermobacter thermautotrophicus (16), a heat shock gene regulator (Phr) from P. furiosus (17), and TrmB for the trehalose/maltose ABC transporter from Thermococcus litoralis and P. furiosus $(18,19)$.

$\operatorname{TrmB}$ is the transcriptional repressor for the gene cluster encoding the trehalose/maltose $\mathrm{ABC}$ transporter in hyperthermophilic archaea T. litoralis and P. furiosus (18). This gene cluster is identical in both species (20) and consists of the genes malE, malF, malG, tre T, trmB, and malK (21-23). The DNA binding sites for TrmB overlap the BRETATA box of the malE operon. TrmB also binds to an inverted repeat sequence upstream of the BRE-TATA box and in front of frk, a gene divergently oriented to malE and encoding an ATP-dependent fructokinase (24). The transcriptional repression of the malE operon by $\operatorname{TrmB}$

* The costs of publication of this article were defrayed in part by the payment of page charges. This article must therefore be hereby marked "advertisement" in accordance with 18 U.S.C. Section 1734 solely to indicate this fact.

The atomic coordinates and structure factors (code 2F5T) have been deposited in the Protein Data Bank, Research Collaboratory for Structural Bioinformatics, Rutgers University, New Brunswick, NJ (http://www.rcsb.org/).

To whom correspondence should be addressed. Tel.: 49-7531-882206; Fax: 49-7531883183; E-mail wolfram.welte@uni-konstanz.de. in an in vitro transcription assay is overcome by the substrates of the trehalose/maltose $\mathrm{ABC}$ transporter (i.e. maltose and trehalose) (18). Recently, a second operon in P. furiosus encoding an ABC transporter for maltodextrins was identified (25). The gene cluster encoding this transporter of $P$. furiosus consists of $m d x E$ encoding the substrate-binding protein (PF1938), $m d x F$ and $m d x G$ encoding the two transmembrane permeases (PF1937 and 1936), pulA encoding amylopullulanase (PF1935), and $m d x K$ encoding the ATP-hydrolyzing protein of the transporter (PF1933). MdxE, carrying the substrate recognition site of the transporter, has been crystallized with bound maltotriose (26). Thus, the maltodextrin $\mathrm{ABC}$ transporter is distinct in its substrate specificity from the trehalose/maltose $\mathrm{ABC}$ transporter, which recognizes maltose and trehalose but not maltodextrins. Recently, we found that TrmB also controls the $m d x E$ operon of $P$. furiosus as a transcriptional repressor and showed that repression is abolished by maltotriose and sucrose but not by maltose or trehalose (19). Therefore, TrmB appears to act as a bifunctional transcription regulator acting on two different promoters and being differentially controlled by binding to different sugars. We constructed a truncated form of TrmB in which the N-terminal DNA binding domain (amino acids 2-109) is deleted. In contrast to the full-length protein (which is dimeric) the truncated form behaved as a monomer during molecular sieve chromatography. Its binding affinity for the various substrates was increased, but its sigmoidal binding characteristic toward maltose could no longer be observed. Here, we report the crystal structure of the truncated form of TrmB. The structure contains bound maltose and represents a novel form of a sugar binding fold. Since the binding of the different sugars results in differential operator recognition, they will elicit differential conformational changes in the intact repressor protein.

\section{EXPERIMENTAL PROCEDURES}

Construction of Truncated TrmB Proteins-All truncated TrmB mutants were cloned into pCS19, resulting in C-terminal His tag versions. We used $5^{\prime}$ target sequence primers containing an NcoI site (CCATGG) and a $3^{\prime}$ end encompassing the sequence primer of TrmB containing the BamHI site. PCR products and vector plasmid were digested with NcoI and BamHI and were ligated by T4 ligase. The resulting plasmids containing the target inserts began with methionine as the first translated codon within the NcoI site. The constructed plasmids were called pSL189, pSL190, and pSL191 for $\Delta 2-30, \Delta 2-59$, and $\Delta 2-109$, respectively. We transformed the constructed plasmids into Escherichia coli SF120 competent cells and purified the three mutants truncated in the N-terminal DNA binding domain, $\Delta 2-30, \Delta 2-59$, and $\Delta 2-109 \mathrm{TrmB}$, by $\mathrm{Ni}^{2+}-\mathrm{NTA}^{2}$ affinity chromatography.

Site-directed Mutation Analysis in the Sugar Binding Motif of TrmBWe prepared coupled primers (codon and noncodon strands of the same length) containing a target site mutation in the middle position (MWG Biotech). 100 ng of plasmid DNA encoding $\operatorname{TrmB}_{\Delta 2-109}$ was

${ }^{2}$ The abbreviation used is: NTA, nitrilotriacetic acid. 


\section{Crystal Structure of TrmB Sugar Binding Domain}

used as template DNA for PCR with $20 \mathrm{pmol}$ of both primers, $0.2 \mathrm{~mm}$ dNTP mixture, and 1.5 units of Pwo polymerase. The PCR protocol was $94{ }^{\circ} \mathrm{C}$ for $30 \mathrm{~min}, 55^{\circ} \mathrm{C}$ for $45 \mathrm{~min}$, and a long extension phase at $72{ }^{\circ} \mathrm{C}$ for $12 \mathrm{~min} .16$ cycles were performed. PCR products were purified by the Qiagen extraction kit. The eluted DNA samples were directly digested by DpnI for selective degradation of methylated template DNA for $1 \mathrm{~h}$ at $37^{\circ} \mathrm{C}$. DNAs were directly transformed into the $E$. coli SF 120 competent cells. The transformants were selected on ampicillin $(100 \mu \mathrm{g} / \mathrm{ml})$-containing LB plates. The plasmid DNAs were prepared by a plasmid miniprep kit (Qiagen). All site-directed mutations were checked by sequencing analysis (GATC Biotech, Konstanz, Germany).

Protein Purification and Molecular Sieve Chromatography-For the expression of truncated TrmB and the site-directed mutation proteins derived from it, cells were grown in 1 liter of NZA medium (10 g of NZ-amine A, $5 \mathrm{~g}$ of yeast extract, $7.5 \mathrm{~g}$ of $\mathrm{NaCl} /$ liter) and $100 \mu \mathrm{g}$ of ampicillin/ml at $30{ }^{\circ} \mathrm{C}$. $0.2 \mathrm{~mm}$ isopropyl 1 -thio- $\beta$-D-galactopyranoside was added after the culture had reached OD 0.7 at $578 \mathrm{~nm}$. Cells were grown for an additional $5 \mathrm{~h}$ at $37^{\circ} \mathrm{C}$ and harvested by centrifugation. The pellet was resuspended in $20 \mathrm{ml}$ of $\mathrm{Ni}^{2+}$-NTA affinity solution (buffer I; $50 \mathrm{~mm}$ sodium phosphate, $300 \mathrm{~mm} \mathrm{NaCl}, \mathrm{pH}$ 7.5), ruptured in a French pressure cell at 16,000 p.s.i., and centrifuged for $30 \mathrm{~min}$ at $17,300 \times g$. The supernatant was heated to $80{ }^{\circ} \mathrm{C}$ for $10 \mathrm{~min}$. After centrifugation of the precipitated proteins, the supernatant was loaded onto a $\mathrm{Ni}^{2+}$-NTA superflow column from Qiagen equilibrated with buffer I. The column was washed with $50 \mathrm{~mm}$ imidazole and eluted with 250 mm imidazole, both in the same buffer. Protein-containing fractions were pooled and dialyzed against $200 \mathrm{~mm}$ sodium phosphate buffer, $\mathrm{pH}$ 8.0. TrmB ${ }_{\Delta 2-109}$ was extremely well induced by $0.2 \mathrm{~mm}$ isopropyl 1-thio$\beta$-D-galactopyranoside and remained soluble during incubation at $80^{\circ} \mathrm{C}$, allowing for removal of $E$. coli proteins. The final concentration of pure $\operatorname{TrmB}_{\Delta 2-109}$ was about $1.0 \mathrm{mg} / \mathrm{ml}$. It was kept frozen at $-70{ }^{\circ} \mathrm{C}$.

For molecular sieve chromatography of $\operatorname{TrmB}_{\Delta 2-109}$, we used Superdex 200 HR10/30 (Amersham Biosciences) with equilibration buffer, 50 $\mathrm{mM}$ HEPES, $\mathrm{pH} 7.5,300 \mathrm{~mm} \mathrm{KCl}$, and $0.4 \mathrm{ml} / \mathrm{min}$ as the rate of elution. Despite the fact that wild type TrmB is retained by a Superdex column (19), the truncated protein was successfully separated by this type of material. The column was calibrated by molecular mass standard: chymotrypsinogen A, $25 \mathrm{kDa}$; ovalbumin, $43 \mathrm{kDa}$; bovine serum albumin, $67 \mathrm{kDa}$; and aldolase, $158 \mathrm{kDa}$ (Amersham Biosciences). Native molecular weight was calculated by comparison with standard marker proteins.

Protein Purification Prior to Crystallization Experiments-Cells were grown as described above, but the cell pellet was resuspended in running buffer consisting of $50 \mathrm{~mm}$ Tris- $\mathrm{HCl}$, pH 8.0, $200 \mathrm{mM} \mathrm{NaCl}$, and 50 $\mathrm{mm}$ imidazole. Cells were ruptured twice in a French pressure cell at 11,000 p.s.i. and subsequently centrifuged for $30 \mathrm{~min}$ at $50,000 \times g$. The supernatant was incubated at $80^{\circ} \mathrm{C}$ for $20 \mathrm{~min}$, and after centrifuging for 60 min at $100,000 \times g$, the supernatant was loaded onto an $\mathrm{Ni}^{2+}-\mathrm{NTA}$ superflow column from Qiagen equilibrated with running buffer. After it was loaded, the column was washed with running buffer and eluted with elution buffer (50 mM Tris, pH 8.0, $200 \mathrm{~mm} \mathrm{NaCl}, 250 \mathrm{~mm}$ imidazole) using a three-step gradient. The protein eluted at the final step (100\% elution buffer) and was afterward concentrated in elution buffer (preventing protein precipitation) using Vivaspin concentrators from Vivascience equipped with a $10-\mathrm{kDa}$ cut-off membrane. Final protein concentration was $10 \mathrm{mg} / \mathrm{ml}$, determined using the extinction coefficient at $280 \mathrm{~nm}$ calculated according to Gill and Hippel (27).

Protein Crystallization and Data Collection-Crystals of $\operatorname{TrmB}_{\Delta 2-109}$ were obtained using the sitting drop vapor diffusion method. $2 \mu \mathrm{l}$ of protein solution $(10 \mathrm{mg} / \mathrm{ml}$ in $50 \mathrm{~mm}$ Tris- $\mathrm{HCl}, \mathrm{pH}$ 8.0, $200 \mathrm{~mm} \mathrm{NaCl}$,
$250 \mathrm{~mm}$ imidazole, $10 \mathrm{~mm}$ maltose) were mixed with $2 \mu \mathrm{l}$ of reservoir solution containing $100 \mathrm{~mm}$ sodium acetate trihydrate, $\mathrm{pH} 4.6$, and $8 \%$ (w/v) PEG 4000 and equilibrated against the reservoir solution at $18^{\circ} \mathrm{C}$. Trigonal crystals (space group $\mathrm{P}_{2} 21$ ) grew to a size of $\sim 50 \times 40 \times 50$ $\mu \mathrm{m}^{3}$. Heavy atom derivatives were obtained by soaking the native crystals in reservoir solution containing in addition $1 \mathrm{~mm}$ platinum and 1 mM uranylacetate, respectively. Soaking time was $4 \mathrm{~h}$ for the platinum derivatives and $10 \mathrm{~min}$ for the uranylacetate derivatives. Diffraction data were collected under cryogenic conditions. The crystals were flash frozen in liquid nitrogen in buffer corresponding to the equilibrated crystallization drops plus 20\% (v/v) glycerol as a cryoprotectant. All data sets were collected at the Swiss Light Source (SLS; beamline X06SA) provided with a MarCCD detector and were processed using XDS (28) and subsequently merged in XSCALE. More details of the data collection statistics are shown in Table 2.

Crystal Structure Determination and Refinement-The crystallographic phase problem was solved by multiple isomorphous replacement plus anomalous differences using one native data set, one platinum derivative data set, one uranylacetate derivative data set, and one native data set measured at a wavelength of $1.5 \AA$, allowing the search for the anomalous signal of the sulfur atoms inherent to the protein. The multiple isomorphous replacement plus anomalous differences experiment was done using the program suites SOLVE (29) and RESOLVE (30). One platinum site, one uranylacetate site, and four sulfur sites were found by SOLVE and used to determine initial phases. Subsequently, RESOLVE led to an interpretable electron density map and an initial model.

Model building and refinement was done using the CCP4 suite (31) and the graphical model building program COOT (32) for visual inspection and manual improvement of the model. Side chain atoms as well as other missing parts of the structure were added manually, followed by refinement cycles, including anisotropic B-factor refinement in REFMAC5 $(33,34)$. Model statistics are summarized in Table 3.

Sugar Binding and Inhibition Assay by $\operatorname{TrmB}$-The binding tests were done by the ammonium sulfate precipitation method (35). A 100- $\mu$ l aliquot of $50 \mathrm{~mm}$ HEPES, pH 7.5, $300 \mathrm{~mm} \mathrm{KCl}$ containing 3.4 or $6.8 \mu \mathrm{M} \mathrm{TrmB}_{\Delta 2-109}$ was incubated with $0.1 \mu \mathrm{Ci}$ of $\left[{ }^{14} \mathrm{C}\right]$ maltose $(0.65$ $\mu \mathrm{M})$ (Amersham Biosciences), $\left[{ }^{14} \mathrm{C}\right]$ maltotriose $(0.47 \mu \mathrm{M}),\left[{ }^{14} \mathrm{C}\right]$ sucrose (0.4 or $0.8 \mu \mathrm{M})$ (Amersham Biosciences), or ${ }^{14} \mathrm{C}$-glucose $(8 \mu \mathrm{M})$ (PerkinElmer Life Sciences). $\left[{ }^{14} \mathrm{C}\right]$ Maltotriose was synthesized from $\left[{ }^{14} \mathrm{C}\right]$ maltose by the action of E. coli amylomaltase without loss of specific activity (36). Prior to their addition, the labeled sugars had been mixed with unlabeled sugars to reach a final concentration between 5 and $1,000 \mu \mathrm{M}$. Incubation was for $5 \mathrm{~min}$ at $70{ }^{\circ} \mathrm{C}$. The assay was stopped with $2 \mathrm{ml}$ of ice-cold saturated ammonium sulfate in binding buffer and kept on ice for $10 \mathrm{~min}$. The suspension was then filtered through cellulose nitrate membrane filters (Schleicher \& Schüll; pore size $0.45 \mu \mathrm{m}$ ) and washed with $1 \mathrm{ml}$ of $95 \%$ saturated ammonium sulfate in binding buffer. Bound radioactivity was determined in a scintillation counter. Also, labeled sugar-binding inhibition assays with other sugars (maltose, maltotriose, sucrose, and glucose) were done in the same way with inhibiting sugars present between 25 and $500 \mu \mathrm{M}$, respectively.

\section{RESULTS}

Purification of Truncated TrmB-Mainly due to the tendency of TrmB to precipitate from solutions exceeding $1 \mathrm{mg} / \mathrm{ml}$, attempts to crystallize the full-length TrmB protein have so far not been successful. Because of our experience that eubacterial repressor fragments can be crystallized after deletion of the N-terminal DNA binding domain, we constructed several $\mathrm{N}$-terminal truncated $\mathrm{TrmB}$ variants as $\mathrm{C}$-terminal 


\section{Crystal Structure of TrmB Sugar Binding Domain}

His tag versions and tested them for maltose-binding affinity. Of three constructs $(\Delta 2-32, \Delta 2-59 \text {, and } \Delta 2-109)^{3}$ only one $(\Delta 2-109)$ was not degraded, was highly soluble, and was expressed in large amounts after induction with $0.2 \mathrm{~mm}$ isopropyl 1-thio- $\beta$-D-galactopyranoside. $\mathrm{TrmB}_{\Delta 2-109}$ was homogeneous on SDS-PAGE after $\mathrm{Ni}^{2+}$-NTA affinity chromatography. From 1 liter of rich medium, $20 \mathrm{mg}$ of pure $\operatorname{TrmB}_{\Delta 2-109}$ was routinely obtained. The protein was stored frozen in 50 $\mathrm{mM}$ HEPES, pH 7.5, $300 \mathrm{mM} \mathrm{KCl}$ at a protein concentration of $1 \mathrm{mg} / \mathrm{ml}$ without loss of maltose binding activity.

Using molecular sieve chromatography (Superdex 200) in $50 \mathrm{~mm}$ HEPES, pH 7.5, $300 \mathrm{~mm} \mathrm{KCl}$ at room temperature $\operatorname{TrmB}_{\Delta 2-109}$ eluted with a peak corresponding to a species of $30 \mathrm{kDa}$ (Fig. $1 A$ ), indicating that the protein was monomeric. However, the peak showed considerable trailing, which reflects interactions with the gel matrix.

Sugar Binding Activity of $\operatorname{TrmB} B_{\Delta 2-109}$-Full-length $\operatorname{TrmB}$ can bind maltose, trehalose, maltotriose, longer maltodextrins, sucrose, and glucose but not fructose, galactose, ribose, and lactose. $\operatorname{TrmB}_{\Delta 2-109}$ showed the same binding specificity but increased binding affinity toward the same sugars compared with intact TrmB. This was particularly evident with maltose as substrate. The binding isotherm for all sugars, including maltose, was hyperbolic and exhibited a stoichiometry of about 1:1 (substrate/polypeptide). It showed the following $K_{d}$ values: $6.8 \mu \mathrm{M}$ for maltose, $25 \mu \mathrm{M}$ for glucose, $34 \mu \mathrm{M}$ for sucrose, and $160 \mu \mathrm{M}$ for maltotriose (Fig. 2). Inhibition studies (Table 1) showed mutual competitiveness, indicating that all sugars were bound at the same site. We emphasize that binding of these sugars by full-length $\operatorname{TrmB}$ is sigmoidal only for maltose (18). Applying the criteria described previously (18), sigmoidality could not be detected in the binding kinetics of maltose in $\operatorname{TrmB}_{\Delta 2-109}$.

Crystal Structure of $\operatorname{Trm} B_{\Delta 2-109}$ - The crystals were trigonal, $\mathrm{P}_{2} 21$, with unit cell axes of $a=b=56.9 \AA, c=132.5 \AA$, and contained one

${ }^{3}$ In the following, amino acids are numbered as in the full-length protein.

$\operatorname{TrmB}_{\Delta 2-109}$ in the asymmetric unit. Experimental phases were obtained by isomorphous replacement and anomalous scattering (see "Experimental Procedures" and Tables 2 and 3). Fig. 3 shows the structure of $\operatorname{TrmB}_{\Delta 2-109}$ in a ribbon representation.

$\mathrm{TrmB}_{\Delta 2-109}$ consists of two domains, termed the $\mathrm{N}$ - and C-domains, formed by residues Ala ${ }^{110}-\mathrm{Gly}^{246}$ and $\mathrm{Lys}^{249}-\mathrm{Ser}^{342}$, respectively. The two residues $\mathrm{Asn}^{247}$ and Pro ${ }^{248}$ may serve as a hinge. The $\mathrm{N}$-domain

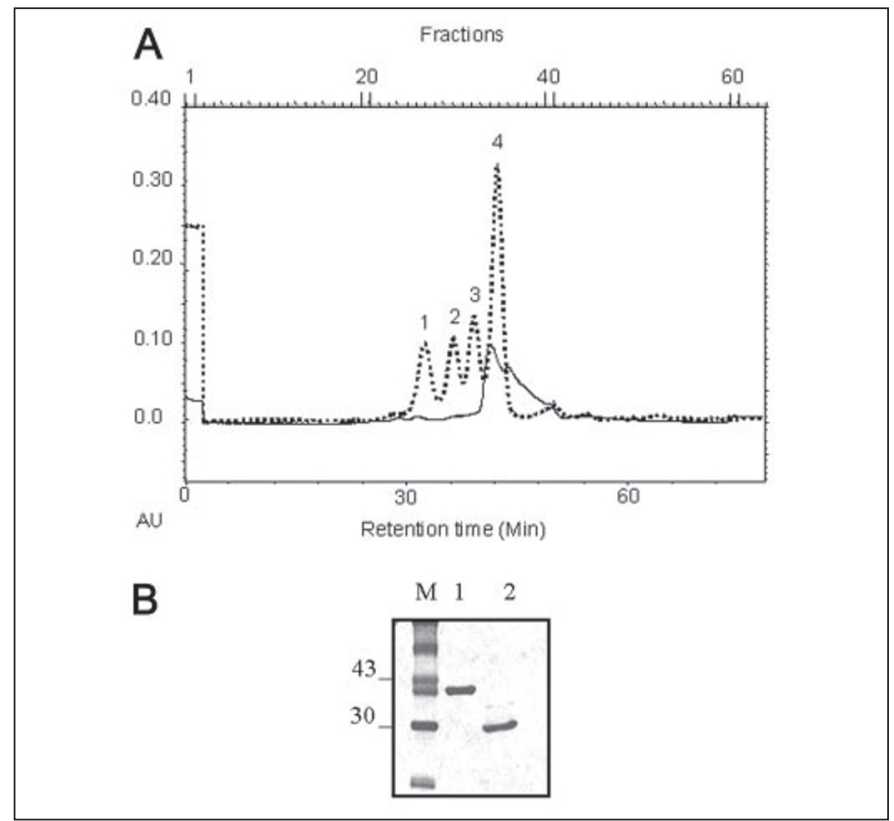

FIGURE 1. Molecular sieve chromatography of $\mathrm{TrmB}_{\Delta 2-109}$ and protein profile. $A$, molecular sieve chromatography of $\mathrm{TrmB}_{\Delta 2-109}$. The dotted line indicates molecular mass standards for aldolase (158 kDa) (1), bovine serum albumin (67 kDa) (2), ovalbumin (43 kDa) (3), and chymotrypsinogen A $(25 \mathrm{kDa})(4)$. The apparent molecular weight was calculated by comparison with the standard marker proteins. These data show that $\operatorname{TrmB}_{\Delta 2-109}$ is monomeric. B, SDS-PAGE of wild type TrmB (lane 1) and $\operatorname{TrmB}_{\Delta 2-109}$ (lane 2).

A

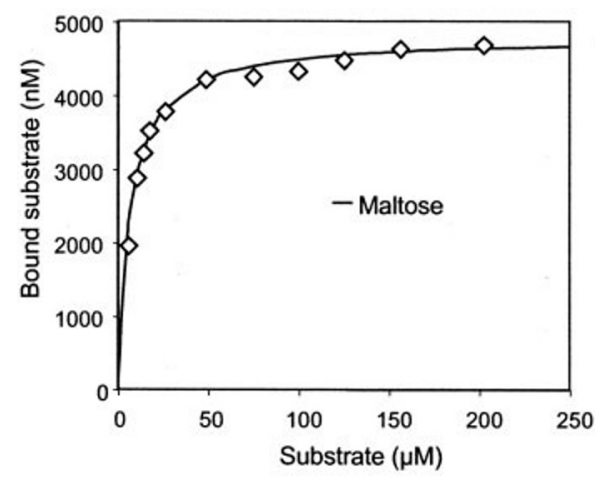

$\mathrm{C}$

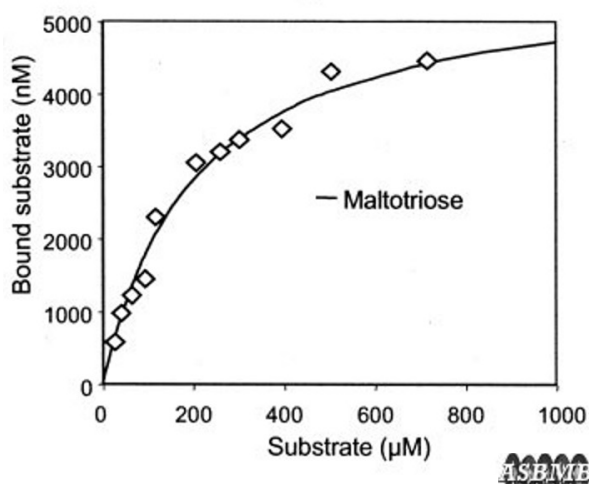

B

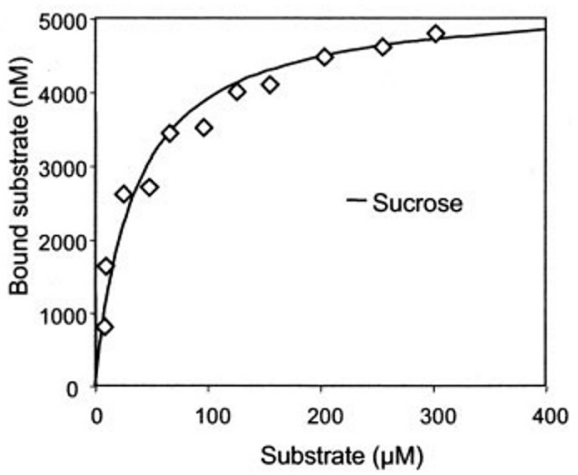

$\mathrm{D}$

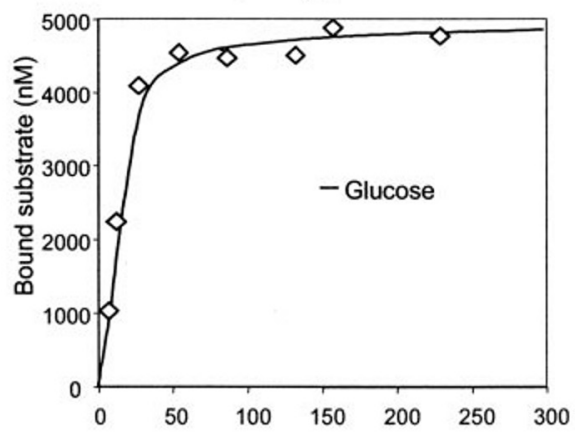

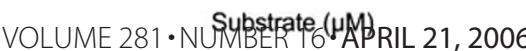




\section{Crystal Structure of TrmB Sugar Binding Domain}

TABLE 1

Inhibition of binding of labeled substrate to $\operatorname{TrmB}_{\Delta 2-109}$ by unlabeled sugars

${ }^{14} \mathrm{C}$-Labeled sugars were present at $0.65,0.47,0.4$, and $8 \mu \mathrm{M}$ initial concentration for maltose, maltotriose, sucrose, and glucose, respectively. TrmB ${ }_{\Delta 2-109} \operatorname{concentration~was~}$ $3.4 \mu \mathrm{M}$. The values indicate the ratios of the amounts of bound labeled sugar in the presence and absence of competing unlabeled sugar in percent.

\begin{tabular}{|c|c|c|c|c|c|c|c|c|c|c|c|c|}
\hline \multirow{2}{*}{ Bound labeled sugar } & \multicolumn{3}{|c|}{ Maltose } & \multicolumn{3}{|c|}{ Maltotriose } & \multicolumn{3}{|c|}{ Sucrose } & \multicolumn{3}{|c|}{ Glucose } \\
\hline & $25 \mu \mathrm{M}$ & $50 \mu \mathrm{M}$ & $100 \mu \mathrm{M}$ & $100 \mu \mathrm{M}$ & $250 \mu \mathrm{M}$ & $500 \mu \mathrm{M}$ & $50 \mu \mathrm{M}$ & $100 \mu \mathrm{M}$ & $250 \mu \mathrm{M}$ & $50 \mu \mathrm{M}$ & $100 \mu \mathrm{M}$ & $250 \mu \mathrm{M}$ \\
\hline & $\%$ & $\%$ & $\%$ & $\%$ & $\%$ & $\%$ & $\%$ & $\%$ & $\%$ & $\%$ & $\%$ & $\%$ \\
\hline Maltose & 29.0 & 12.0 & 9.5 & 86.5 & 58.2 & 48.4 & 31.1 & 18.5 & 9.4 & 22.3 & 9.5 & 3.9 \\
\hline Maltotriose & 32.4 & 6.5 & 4.2 & 73.3 & 48.2 & 32.3 & 51.1 & 30.6 & 13.7 & 13.0 & 9.7 & 7.6 \\
\hline Sucrose & 58.1 & 28.2 & 14.6 & 73.0 & 55.1 & 38.2 & 51.4 & 31.1 & 15.5 & 15.4 & 8.1 & 4.2 \\
\hline Glucose & 5.0 & 3.2 & 3.0 & 100. & 59.8 & 41.5 & 38.0 & 19.0 & 8.6 & 41.1 & 26.5 & 11.9 \\
\hline
\end{tabular}

TABLE 2

Summary of data collection

\begin{tabular}{|c|c|c|c|c|c|c|}
\hline & \multicolumn{3}{|c|}{ Native } & \multicolumn{3}{|c|}{ Derivative } \\
\hline & TrmB 1 & TrmB 2 & TrmB merged & TrmB-Pt & $\mathrm{TrmB}-\mathrm{UO}_{2} \mathrm{Ac}_{2}$ & TrmB-S \\
\hline Wavelength (§̊) & 0.850 & 0.978 & & 0.979 & 0.979 & 1.699 \\
\hline Cell $(\AA)$ & $56.8,56.8,132.3$ & $56.8,56.8,132.5$ & $56.9,56.9,132.5$ & $57.1,57.1,132.9$ & $56.8,56.8,132.5$ & $56.8,56.8,132.0$ \\
\hline Resolution range $(\AA)$ & $44-1.84(1.94-1.83)$ & $44-1.45(1.54-1.45)$ & $44-1.45(1.54-1.45)$ & $44-3.04(3.23-3.04)$ & $44-1.73(1.84-1.73)$ & $44-2.08(2.21-2.08)$ \\
\hline No. of unique reflections & 41,989 & 43,837 & 44,046 & 9,229 & 49,611 & 27,781 \\
\hline Average multiplicity & $3.75(3.44)$ & $10.47(8.69)$ & $13.99(8.67)$ & $4.04(2.3)$ & $5.29(2.77)$ & $11.16(10.19)$ \\
\hline$R_{\text {mrgd-F }}(\%)(43)$ & $5.1(18.4)$ & $3.4(20.5)$ & $3.3(21.1)$ & $7.3(32.3)$ & $12.2(69.8)$ & $4.7(13.3)$ \\
\hline Completeness (\%) & $99.4(96.8)$ & $98.0(93.3)$ & $88.0(90.3)$ & $99.1(95.6)$ & $99.5(97.0)$ & $97.8(95.0)$ \\
\hline$I / \sigma_{I}$ & $21.1(7.3)$ & $33.5(7.3)$ & $35.8(7.9)$ & $15.6(3.4)$ & $9.3(1.8)$ & $20.5(9.5)$ \\
\hline
\end{tabular}

\section{TABLE 3}

\section{Refinement statistics}

Values given in brackets are for the highest resolution shell (1.49-1.45 $)$.

\begin{tabular}{lc}
\hline \multicolumn{1}{c}{ Parameters } & Values \\
\hline Protein atoms & 1,966 \\
Ligand atoms & 46 \\
Solvent molecules & 106 \\
Resolution range & $40-1.45(1.49-1.45)$ \\
$R$-factor (\%) & $16.2(17.2)$ \\
$R$-free (\%) & $19.5(28.3)$ \\
Total number of reflections & $41,765(2,893)$ \\
Reflections in test set & $2,224(150)$ \\
Reflections in working set & $39,541(2,743)$ \\
$B$-factor of protein atoms $\left(\AA^{2}\right)$ & 16.0 \\
$B$-factor of all atoms $\left(\AA^{2}\right)$ & 16.2 \\
Root mean square deviation bonds ( $(\AA)$ & 0.017 \\
Root mean square deviation angles (degrees) & 1.822 \\
No. of residues with backbone conformational & $191(91.4 \%)$ \\
angles in most favored regions & $17(8.1 \%)$ \\
No. of residues with backbone conformational & angles in additional allowed regions \\
No. of residues with backbone conformational & $1(0.5 \%)$ \\
$\quad$ angles in generously allowed regions & $0(0 \%)$ \\
No. of residues with backbone conformational & \\
angles in disallowed regions &
\end{tabular}

forms an 8-stranded sheet flanked by two large helices on one side and one large helix crossing the $\beta$-sheet on the other side. Because the latter helix provides the only maltose-binding residues of the $\mathrm{N}$-domain, we shall designate it as the "sugar binding helix" in the following. The C-domain forms a strand, a helix, and an irregular, flattened, seven-stranded $\beta$-barrel with its axis roughly parallel to the strands of the $\mathrm{N}$-domain sheet. Most of the residues binding the nonreducing part of the maltose molecule are contributed by two neighboring loops of the C-domain barrel.

Maltose Binding in $\operatorname{Trm}_{\Delta 2-109}$ - In the interstice between the two domains of $\operatorname{TrmB}_{\Delta 2-109}$, electron density corresponding to maltose ( $\alpha$-D-glucosyl-1,4- $\alpha$-D-glucose) was visible (Figs. 3 and 4). The nonreducing glucosyl residue of maltose forms hydrogen bonds with residues $\mathrm{Asn}^{305}, \mathrm{Gly}^{320}, \mathrm{Met}^{321}, \mathrm{Val}^{324}, \mathrm{Ile}^{325}$, and $\mathrm{Glu}^{326}$. All residues with the exception of $\mathrm{Ser}^{229}$ are in the $\mathrm{C}$-domain and part of the $\beta$-sheet $\left(\mathrm{Asn}^{305}\right)$ as well as part of a loop region $\left(\mathrm{Gly}^{320}, \mathrm{Met}^{321}, \mathrm{Val}^{324}, \mathrm{Ile}^{325}\right.$, and $\mathrm{Glu}^{326}$ ). $\mathrm{Ser}^{229}$ in the sugar binding helix of the $\mathrm{N}$-domain contributes the only hydrogen bond contacting the reducing glucosyl moiety of maltose.

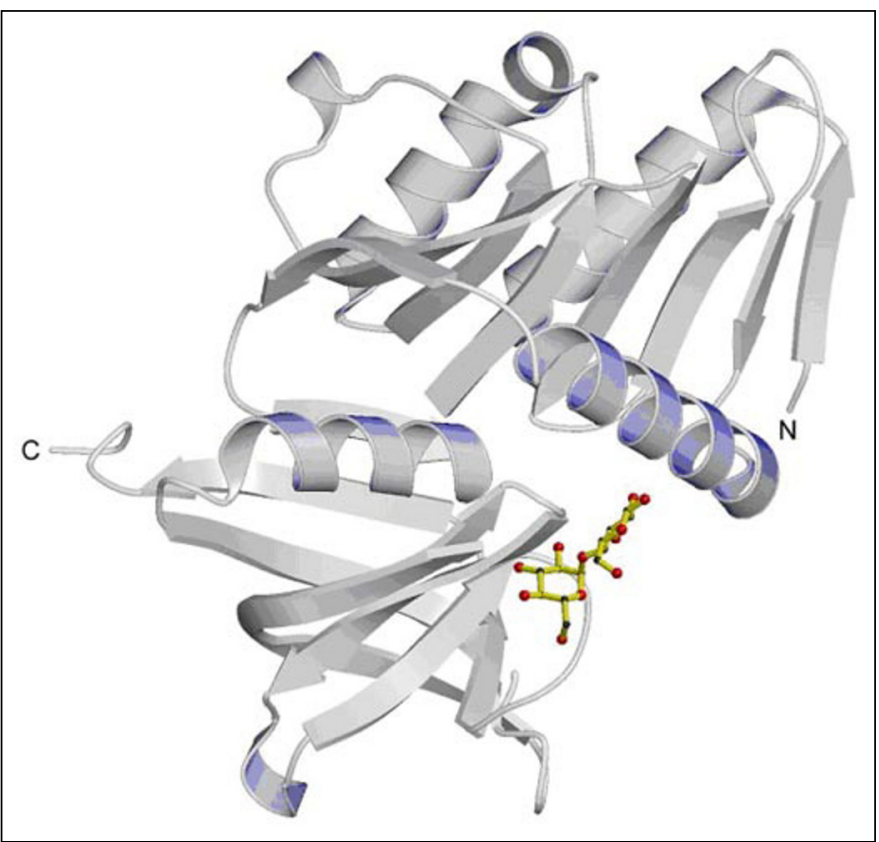

FIGURE 3. Crystal structure of $\operatorname{TrmB}_{\Delta \mathbf{2 - 1 0 9}}$. The protein and the bound maltose are indicated as a ribbon and ball and stick representation, respectively. Maltose is bound with its nonreducing glucosyl residue toward the barrel domain. The $\mathrm{N}$ and $\mathrm{C}$ termini of the fragment are labeled.

Based on the observed mode of binding for maltose, it appears likely that all substrates are bound with their nonreducing $\alpha$-glucosyl moiety to the same six amino acid residues of the C-domain. Obviously, the fixation of the common nonreducing glucosyl residue is the basis for the surprisingly large range of different substrates. Four of the maltoseinteracting residues $\left(\mathrm{Ser}^{229}, \mathrm{Asn}^{305}, \mathrm{Gly}^{320}\right.$, and $\mathrm{Glu}^{326}$ ) were changed by site-directed mutagenesis into alanine, and the purified proteins were analyzed for their binding affinity to maltose, maltotriose, sucrose, and glucose (Table 4). Whereas the mutant E326A lost all sugar binding affinity, mutants D305A and G320A showed reduced affinity. The mutant S229A showed reduced binding affinity only for maltose and maltotriose, whereas the affinity for sucrose and glucose remained the same as with the nonmutated $\operatorname{TrmB}_{\Delta 2-109}$. 
FIGURE 4. Detail of TrmB $\mathrm{B}_{\Delta 2-109}$ around the maltose binding site in stereo. The bound maltose and amino acid residues involved in binding are indicated as ball and stick models. The nonreducing glucosyl residue of maltose is oriented to the right. Residue numbers are indicated and correspond to the wild type protein. The $5 \sigma$ level of the omit map of the bound maltose is shown as a blue surface.

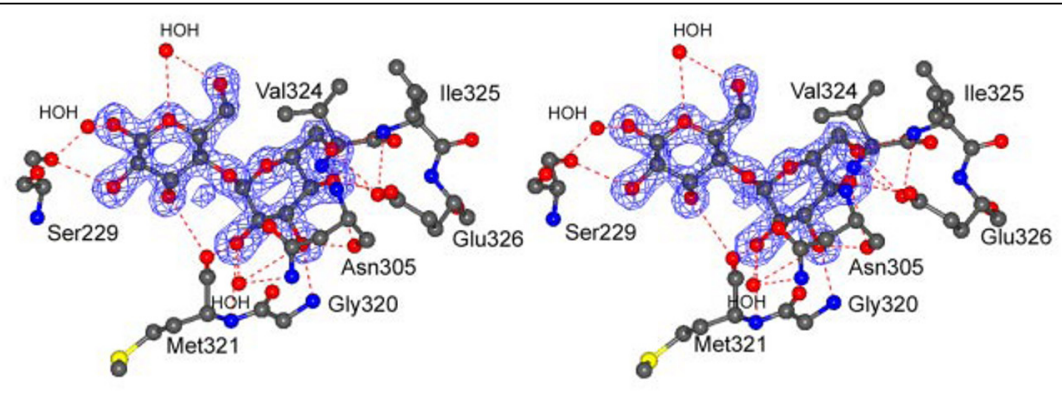

\section{TABLE 4}

$K_{d}$ values for sugar binding to $\operatorname{TrmB}_{\Delta 2-109}$ and site-directed mutants

Shown are $K_{d}$ values $(\mu \mathrm{M})$ of site-directed mutants of $\operatorname{TrmB}_{\Delta 2-109}$ at a protein concentration of $3.4 \mu \mathrm{M}$. -, no binding; ND, not determined.

\begin{tabular}{|c|c|c|c|c|}
\hline Proteins & Maltose & Glucose & Sucrose & Maltotriose \\
\hline & \multicolumn{4}{|c|}{$\mu M$} \\
\hline $\operatorname{TrmB}_{\Delta 2-109}$ & 6.8 & 25 & 34 & 160 \\
\hline S229A & 10 & 25 & 35 & 250 \\
\hline N305A & 50 & 100 & 80 & 1,000 \\
\hline G320A & 250 & 150 & 200 & $>2,000$ \\
\hline E326A & - & - & - & - \\
\hline N305A/G320A & - & ND & - & - \\
\hline G320A/E326A & - & - & - & - \\
\hline
\end{tabular}

\section{DISCUSSION}

Comparison with Eubacterial Binding Proteins and Transcriptional Repressors - The maltose binding $\operatorname{TrmB}_{\Delta 2-109}$ structure should be compared with the effector binding domains of the eubacterial lac repressor family members and eubacterial periplasmic binding proteins, which are thought to form a common structural class $(37,38)$. The periplasmic binding proteins are subdivided into groups with one, two, and three switches of the polypeptide between the two domains $(39-41)$. These proteins undergo a large conformational change, moving the two domains against each other in such a way as to bury the substrate between them. The sugar binding pocket of $\operatorname{TrmB}_{\Delta 2-109}$ does not resemble the canonical substrate binding pocket of eubacterial sugarbinding transcriptional regulators and periplasmic binding proteins. Although the $\mathrm{N}$-domain and the barrel domain of $\operatorname{TrmB}_{\Delta 2-109}$ participate in establishing the binding pocket, only the $\alpha$ - $\beta \mathrm{N}$-domain resembles part of the eubacterial proteins, whereas the barrel domain has no counterpart among them.

In addition, whereas isopropyl 1 -thio- $\beta$-D-galactopyranoside, maltose, maltotriose, maltotetraose, and trehalose are bound to the eubacterial proteins deeply in the cleft between both domains and with their axis oriented roughly along the cleft (41), the bound maltose in $\operatorname{TrmB}_{\Delta 2-}$ 109 sticks to the surface-exposed edge of the cleft between the $\mathrm{N}$ - and the C-domain, oriented with its axis roughly perpendicular to the cleft (Fig. 5). The buried surface between the two domains is rich in phenylalanines and other hydrophobic residues, rendering a large movement of these domains in response to the sugar binding rather unlikely.

Alteration of the amino acid residues that are in contact with the bound maltose reveal the special role of $\mathrm{Ser}^{229}$. The change to Ala only affects the binding of maltose and maltotriose but not the binding to sucrose and glucose (see Table 4). $\operatorname{Ser}^{229}$ is the only amino acid that contacts the reducing glucosyl residue of maltose. From these data, it is likely that sucrose interacts with the sugar binding helix on a site different from $\mathrm{Ser}^{229}$. Possibly, it is the differential lateral movement of this helix in response to the binding of the different sugars that elicits the differential response in operator recognition. According to the structure of $\operatorname{TrmB}_{\Delta 2-109}$, the DNA binding domain of the full-length $\operatorname{TrmB}$ is in proximity of the $\mathrm{N}$-terminal end of the sugar binding helix, suggesting

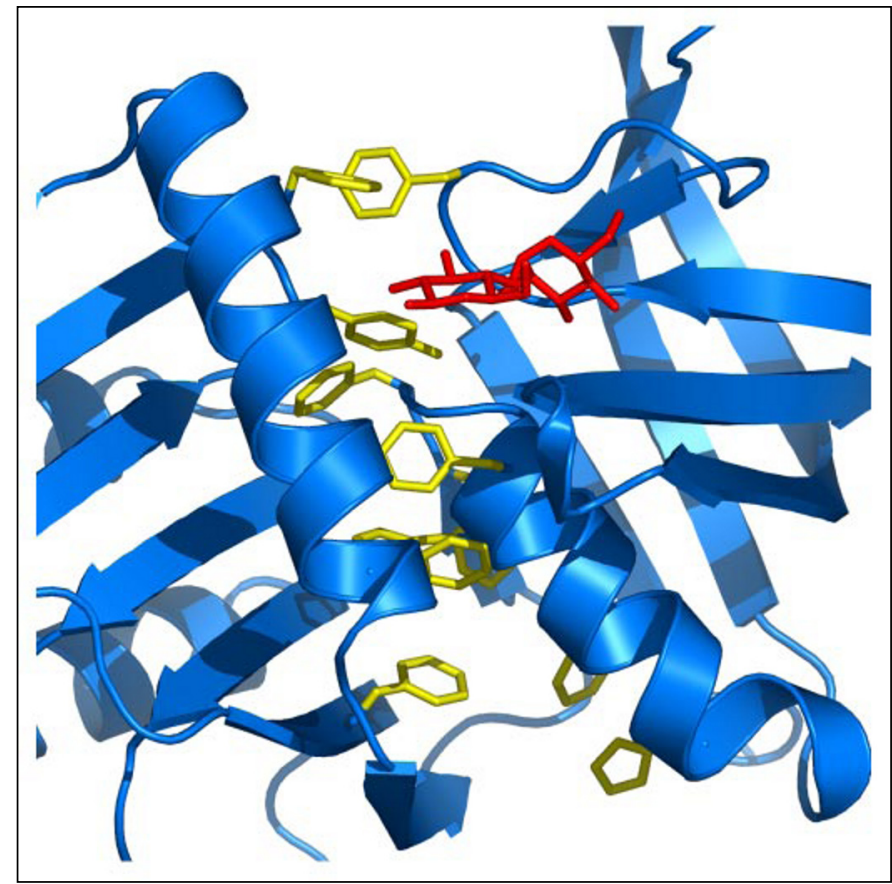

FIGURE 5. Aromatic residues of the interdomain interface. The protein, the bound maltose, and the aromatic residues are indicated as a blue ribbon and a red and yellow bond representation, respectively.

transduction of differential induced fit movements upon sugar binding via this helix.

The $\operatorname{Trm} B_{\Delta 2-109}$ Structure Represents a Novel Sugar-binding Structure-The result of a Dali search (42) with $\operatorname{TrmB}_{\Delta 2-109}$ in the Protein Data Bank is summarized in Table 5. The three highest scores show only similarities between individual structural elements. Chain A of E. coli polyphosphate kinase (Protein Data Bank accession number $1 x d o$ ) yielded the highest score because of a similar barrel domain in both structures. Chain A of the calpain protease core was second because of the good superposition with the sugar binding helix of $\operatorname{TrmB}_{\Delta 2-109}$. Chain A of a biotin ligase was third due to a poor superpo- 


\section{Crystal Structure of TrmB Sugar Binding Domain}

\section{TABLE 5}

Top hits of a Dali search with the structure of $\operatorname{TrmB}_{\Delta 2-109}$

PDB, Protein Data Bank entry code; Z-score, strength of structural similarity in S.D. values above expected according to Ref. 42; RMSD, root mean square deviation of C coordinates of equivalenced residues in $\AA$; LALI, total number of equivalenced residues; IDE, percentage of sequence identity over equivalenced residues.

\begin{tabular}{|c|c|c|c|c|c|}
\hline PDB & Z-score & RMSD & LALI & IDE & Protein \\
\hline & & & & $\%$ & \\
\hline $1 x \mathrm{do}$ & 11.3 & 2.8 & 128 & 11 & E. coli polyphosphate kinase \\
\hline $1 \mathrm{kxr}$ & 5.0 & 3.0 & 76 & 11 & Calcium-bound protease core of calpain I \\
\hline $1 \mathrm{wnl}$ & 4.4 & 1.9 & 45 & 16 & $\begin{array}{l}\text { Biotin-(acetyl-CoA-carboxylase) ligase from } \\
\text { Pyrococcus horikoshii }\end{array}$ \\
\hline
\end{tabular}

FIGURE 6. Putative dimer structure of TrmB $\mathrm{TrmB}_{\Delta 2-109}$ in a ribbon representation with the $\mathrm{N}$ terminus of the fragment in yellow and the two bound maltose molecules in a red bond representation.

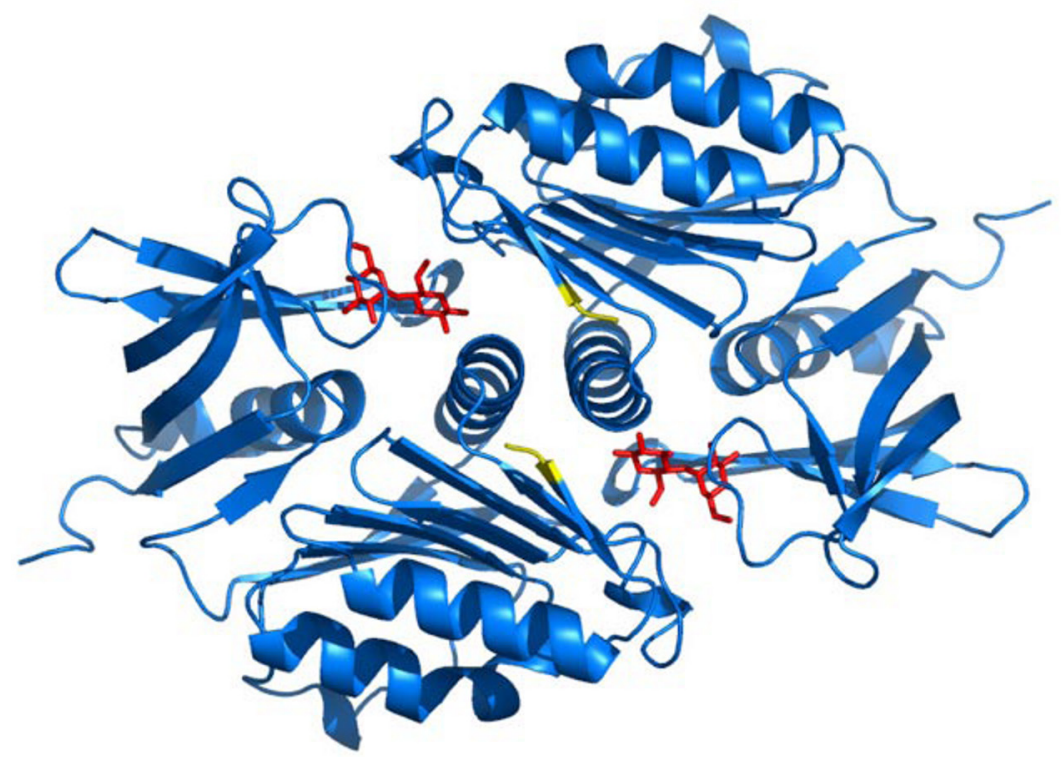

sition with the $\mathrm{N}$-domain of $\operatorname{TrmB}_{\Delta 2-109}$. Thus, the structure and its mode of sugar binding are entirely novel.

The TrmB ${ }_{\Delta 2-109}$ Structure in the Light of the in Vitro DNA Binding and Transcriptional Function of $\operatorname{TrmB}$ - TrmB binding to two intergenic DNA sites has previously been studied by electrophoretic mobility shift assay and footprinting analysis. One site is overlapping with and extending downstream of the BRE-TATA box of the malE operon (TM promoter) from $T$. litoralis and P. furiosus (18). A second site is nearly coincident with the transcriptional start point of the $m d x E$ operon (MD promoter) in $P$. furiosus. The first site contains a palindromic motif 5' -TACTNNNAGTA-3', whereas the second contains a distorted palindromic motif, 5' -TACTNNNATGG-3' (19). From the perfect palindrome of the first site, one can conclude that $\operatorname{TrmB}$ binds there as a dimer with 2-fold symmetry relating one TrmB molecule and half of the palindrome to the remainder of the complex.

In the second site, most likely only the first half of the sequence (5'-TACTNNNA-3') will contribute to the recognition of the TrmB dimer, resulting in a changed $\operatorname{TrmB}$ conformation. This prediction should hold despite the lack of knowledge about the structure of the N-terminal 109 residues of TrmB.

A possible quaternary structure of dimeric TrmB was selected from all crystallographic binary associates of $\operatorname{TrmB}_{\Delta 2-109}$ as the one that buries the largest surface from solvent $\left(2929 \AA^{2}\right)$. In this association, the $\mathrm{N}$ termini are approximately parallel at a distance of only $12.7 \AA$ (Fig. 6). Such a dimer of full-length TrmB would allow for a solvent-sequestered interface between the two DNA binding domains and would resemble several bacterial repressors that also bind to palindromic operators.

TrmB binding to DNA as detected by electrophoretic mobility shift assay as well as transcriptional repression in vitro has been found to be reduced upon the addition of specific sugar molecules $(18,19)$. Surprisingly, the inducibility by some of the sugars depended on the operons to which TrmB was bound, rendering TrmB a bifunctional transcriptional regulator: The TM operon was induced by maltose and trehalose but not by sucrose or maltodextrin, whereas the MD operon was induced by sucrose and maltodextrins but not by maltose or trehalose (19). In the absence of DNA, TrmB binds maltose, sucrose, glucose, maltotriose, and trehalose in decreasing order of affinity, and only maltose is bound in a cooperative manner. The structure of $\mathrm{TrmB}_{\Delta 2-109}$ suggests explanations for these observations. When TrmB docks to the operator in front of the TM operon, due to the perfectly symmetric palindrome a complex of perfect 2-fold symmetry will result, exhibiting increased binding affinity for maltose and trehalose. However, when TrmB binds to the operator in front of the MD operon, due to the broken symmetry of the palindrome, allosteric effects will change the affinities of the sugar binding site so that sucrose and maltodextrins are preferentially bound. The delicate design of the sugar binding site across the cleft of the Nand $\mathrm{C}$-domain, with the common nonreducing end bound to the $\mathrm{C}$-domain and the other end pushing the sugar binding helix of the N-domain, is well suited for such allosteric changes.

\section{REFERENCES}

1. Thomm, M. (1996) FEMS Microbial Rev. 18, 159-171

2. Kyrpides, N. C., and Ouzounis, C. A. (1999) Proc. Natl. Acad. Sci. U. S. A. 96, 8545-8550

3. Soppa, J. (1999) Mol. Microbiol. 31, 1295-1305

4. Geiduschek, E. P., and Ouhammouch, M. (2005) Mol. Microbiol. 56, 1397-14.07

5. Bell, S. D., and Jackson, S. P. (2001) Curr. Opin. Microbiol. 4, 208-213

6. Reeve, J. N. (2003) Mol. Microbiol. 48, 587-598

7. Ouhammouch, M. (2004) Curr. Opin. Genet. Dev. 14, 133-138

8. Bell, S. D. (2005) Trends Microbiol. 13, 262-265 


\section{Crystal Structure of TrmB Sugar Binding Domain}

9. Aravind, L., and Koonin, E. V. (1999) Nucleic Acids Res. 27, 4658-4670

10. Brinkman, A. B., Dahlke, I., Tuininga, J. E., Lammers, T., Dumay, V., de Heus, E., Lebbink, J. H. G., Thomm, M., de Vos, W. M., and van der Oost, J. (2000) J. Biol. Chem. 275, 38160-38169

11. Bell, S. D., and Jackson, S. P. (2000) J. Biol. Chem. 275, 31624-31629

12. Brinkman, A. B., Bell, S. D., Lebbink, R. J., de Vos, W. M., and van der Oost, J. (2002) J. Biol. Chem. 277, 29537-29549

13. Ouhammouch, M., Dewhurst, R. E., Hausner, W., Thomm, M., and Geiduschek, E. P. (2003) Proc. Natl. Acad. Sci. U. S. A. 100, 5097-5102

14. Lie, T. J., Wood, G. E., and Leigh, J. A. (2005) J. Biol. Chem. 280, 5236-5241

15. Bell, S.D., Cairns, S. S., Robson, R. L., and Jackson, S. P. (1999) Mol. Cell 4, 971-982

16. Xie, Y., and Reeve, J. N. (2005) J. Bacteriol. 187, 6419-6429

17. Vierke, G., Engelmann, A., Hebbeln, C., and Thomm, M. (2003) J. Biol. Chem. 278, $18-26$

18. Lee, S-J., Engelmann, A., Horlacher, R., Qu, Q., Vierke, G., Hebbeln, C., Thomm, M., and Boos, W. (2003) J. Biol. Chem. 278, 983-990

19. Lee, S-J., Moulakakis, C., Koning, S. M., Hausner, W., Thomm, M., and Boos, W. (2005) Mol. Microbiol. 57, 1797-1807

20. DiRuggiero, J., Dunn, D., Maeder, D. L., Holley-Shanks, R., Chatard, J., Horlacher, R. Robb, F. T., Boos, W., and Weiss, R. B. (2000) Mol. Microbiol. 38, 684-693

21. Horlacher, R., Xavier, K. B., Santos, H., DiRuggiero, J., Kossmann, M., and Boos, W. (1998) J. Bacteriol. 180, 680-689

22. Greller, G., Horlacher, R., DiRuggiero, J., and Boos, W. (1999) J. Biol. Chem. 274, 20259-20264

23. Qu, Q., Lee, S.-J., and Boos, W. (2004) J. Biol. Chem. 279, 47890-47897

24. Qu, Q., Lee, S.-J., and Boos, W. (2004) Extremophiles 8, 301-308
25. Koning, S. M., Konings, W. N., and Driessen, A. J. M. (2002) Archaea 1, 19-25

26. Evdokimov, A. G., Anderson, D.E., Routzahn, K. M., and Waugh, D. S. (2001) J. Mol. Biol. 305, 891-904

27. Gill, S., and Hippel, P. (1989) Anal. Biochem. 182, 319-326

28. Kabsch, W. (1993) J. Appl. Crystallogr. 26, 795-800

29. Terwilliger, T. C., and J. Berendzen. (1999) Acta Crystallogr. D 55, $849-861$

30. Terwilliger, T. C. (2002) Acta Crystallogr. D 59, 34-44

31. Collaborative Computational Project (1994) Acta Crystallogr. D 50, $760-763$

32. Emsley, P., and Cowtan, K. (2004) Acta Crystallogr. D 60, 2126-2132

33. Murshudov, G. N., Vagin, A. A., and Dodson, E. J. (1997) Acta Crystallogr. D 53, $240-245$

34. Murshudov, G. N., Lebedev, A., Vagin, A. A., Wilson, K. S., and Dodson, E. J. (1999) Acta Crystallogr. D 55, 247-255

35. Richarme, G., and Kepes, A. (1983) Biochim. Biophys. Acta 742, 16-24

36. Dippel, R., and Boos, W. (2005) J. Bacteriol. 187, 8322-8331

37. Lewis, M., Chang, G., Horton, N. C., Kercher, M. A., Pace, H. C., Schumacher, M. A., Brennan, R. G., and Lu, P. (1996) Science 271, 1245-1254

38. Hars, U., Horlacher, R., Boos, W., Welte, W., and Diederichs, K. (1998) Protein Sci. 7, 2511-2521

39. Clarke, T. E., Ku, S.-Y., Dougan, D. R., Vogel, H. J., and Tari, L. W. (2000) Nat. Struct. Biol. 7, 287-291

40. Borths, E. L., Locher, K. P., Lee, A. T., and Rees, D. C. (2002) Proc. Natl. Acad. Sci. U. S. A. 99, 16642-16647

41. Quiocho, F. A., and Ledvina, P. S. (1996) Mol. Microbiol. 20, 17-25

42. Holm, L., and Sander, C. (1993) J. Mol. Biol. 233, 123-138

43. Diederichs, K., Karplus, P.A. (1997) Nat. Struct. Biol. 4, $269-275$ 